\title{
The membrane phospholipids of Neisseria meningitidis and Neisseria gonorrhoeae as characterized by fast atom bombardment mass spectrometry
}

\author{
M. Mahbubur Rahman, ${ }^{1}$ V. S. Kumar Kolli, ${ }^{1}$ Charlene M. Kahler, ${ }^{2}$ \\ Giles Shih, ${ }^{2}$ David S. Stephens ${ }^{2}$ and Russell W. Carlson ${ }^{1}$
}

Author for correspondence: Russell W. Carlson. Tel: +1 706542 4439. Fax: +1 7065424412. e-mail: rcarlson@ccrc.uga.edu

1 Complex Carbohydrate Research Center, The University of Georgia, 220 Riverbend Road, Athens, GA 30602, USA

2 Departments of Medicine and Microbiology and Immunology, Emory University School of Medicine, Atlanta, GA 30303, and Department of Veterans Affairs Medical Center, Atlanta, GA, USA

\begin{abstract}
The phospholipids of Neisseria meningitidis and Neisseria gonorrhoeae were characterized by fast atom bombardment (FAB)-MS and GLC-MS. The major phospholipids were phosphatidylethanolamine (PE), followed by phosphatidylglycerol (PG), with minor amounts of phosphatidic acid (PA) and trace levels of cardiolipin (DPG). All of the phospholipid preparations were variable in their fatty acyl substituents, which included C16:1, C16:0, C18:1, C14:0, C14:1 and C12:0. By MS/MS analysis, all pathogenic Neisseria spp. phospholipids contained a saturated fatty acyl substituent and either a saturated or unsaturated fatty acyl substituent in the sn-1 and sn-2 positions, respectively. Compared with enteric bacterial species, the phospholipids of $N$. meningitidis and $\boldsymbol{N}$. gonorrhoeae have increased levels of phospholipids with short-chain fatty acyl residues (i.e. increases in C12:0, C14:1 and C14:0) and variable amounts of C18:1. The percentage of total PE and PG molecules with the shorter-chain fatty acids ranges from 35 to $47 \%$ and 42 to $66 \%$, respectively, for $N$. meningitidis while these respective values are $<10 \%$ and $<5 \%$ for Escherichia coli. The variability and variety of meningococcal and gonococcal phospholipids suggest novel genetic mechanisms of neisserial phospholipid assembly and regulation, which may be important for the biology and pathogenesis of $\boldsymbol{N}$. meningitidis and $\boldsymbol{N}$. gonorrhoeae.
\end{abstract}

Keywords: Neisseria meningitidis, Neisseria gonorrhoeae, membranes, phospholipids

\section{INTRODUCTION}

Neisseria meningitidis and Neisseria gonorrhoeae, are obligate human pathogens that cause distinctly different disease syndromes. N. meningitidis, which normally colonizes the nasopharynx, is a major cause of sepsis and epidemic meningitis (Brandtzaeg et al., 1989; Virji, 1996). In contrast, N. gonorrhoeae is a major sexually transmitted pathogen causing urethritis, epididymitis, salpingitis and infertility (Handsfield \& Sparling, 1995). However, both pathogens are closely related genetically, colonize human mucosal surfaces and express a similar

Abbreviations: DPG, cardiolipin; FAB, fast atom bombardment; LPA, lysophosphatidic acid; PA, phosphatidic acid; PE, phosphatidylethanolamine; PG, phosphatidylglycerol. array of outer-membrane proteins and lipooligosaccharide (LOS) structures that have defined roles in pathogenesis (Virji, 1996; Nassif \& So, 1995; Kahler \& Stephens, 1998). The contributions of membrane phospholipid structure to the virulence of meningococci and gonococci have not been investigated. Membrane phospholipids are increasingly recognized as important components of bacterial virulence mechanisms, including roles as signalling molecules and toxins (Moolenaar, 1995). The importance of phospholipid structure with respect to bacterial resistance to antimicrobial agents, humoral immune mechanisms and environmental stresses is also recognized (Hancock, 1997; Mold, 1989).

In Gram-negative bacteria, such as Escherichia coli and Neisseria spp., the outer membrane has an asymmetrical organization in which the outer leaflet is primarily composed of LPS and proteins and the inner leaflet 
contains phospholipids (Nikaido, 1996). The role of phospholipids in maintaining the integrity of the outer membrane has been demonstrated. Perturbation of outer-membrane biogenesis in E. coli by mutations which decrease lipid A synthesis (Karow et al., 1992) and suppress outer-membrane protein assembly (Kloser et al., 1998) results in elevated levels of phospholipid synthesis and incorporation into the outer membrane. Since both LPS and phospholipid pathways share common fatty acid precursors, this effect may be mediated by the shift in the flow of these precursors from one pathway to the other. In Proteus mirabilis, it has been noted that LPS mutants contain an increased level of unsaturated fatty acid content which may compensate for fluidity changes in the outer membrane (Rottem et al., 1978). Additionally, the export and trimerization of the major porins of the outer membrane rely upon a tight association with intact LPS, and these proteins do not localize to the outer membrane of E. coli mutants expressing LPS cores deficient in heptose (Sen \& Nikaido, 1991). Interestingly, the relative abundance of membrane phospholipids also significantly affects the functional activities of outer-membrane proteins (Senff et al., 1976; Wolf-Watz et al., 1975).

Earlier studies conducted in the 1960s and 1970s using TLC indicated that the major phospholipid component of membranes isolated from N. gonorrhoeae consisted largely of phosphatidylethanolamine (PE) with varying amounts of phosphatidylglycerol (PG), cardiolipin (DPG) and lysophosphatidylethanolamine (LPE) (Guymon et al., 1978; Sud \& Feingold, 1976; Senff et al., 1976; Wolf-Watz et al., 1975; Lewis et al., 1968; Moss et al., 1970). Subsequently, it was shown that the LPE found in gonococcal membranes was due to the degradation of PE by phospholipase A (Cacciapuoti et al., 1978, 1979). Lauric (C12:0), myristic (C14:0), palmitic (C16:0), palmitoleic (C16:1) and cis-vaccenic (C18:1) acids were the major fatty acids attached to gonococcal phospholipid head groups (Guymon et al., 1978; Sud \& Feingold, 1976; Wolf-Watz et al., 1975; Wilkinson, 1988; Moss et al., 1970; Lewis et al., 1968). The total cellular fatty acids and extractable cellular lipids of $N$. meningitidis isolates were subsequently found to be similar to those of gonococci (Lewis et al., 1968; Moss et al., 1970; Wilkinson, 1988). However, the precise structures of $N$. meningitidis phospholipids, including their fatty acylation patterns, have not been examined in detail.

This study is the first to detail by MS the complete structure of the phospholipids of both N. meningitidis and $N$. gonorrhoeae. In addition, a series of meningococcal capsule and LOS mutants were studied to determine whether changes in the expression of these surface structures affected the phospholipid profile. Considerable heterogeneity was observed in the $N$. meningitidis phospholipid fatty acylation patterns when compared to the phospholipids from various enteric bacterial species. This heterogeneity is likely to be a result of novel genetic mechanisms of neisserial phospholipid assembly and regulation.

\section{METHODS}

Bacterial strains and conditions of growth. Four strains of $N$. meningitidis (NMB, F8229, F8239, 6940) and N. gonorrhoeae FA 1090 were used in these studies, in addition to six genetically defined mutants of meningococcal strain NMB (Table 1). The wild-type meningococcal and gonococcal strains and mutant derivatives of meningococcal strain $\mathrm{NMB}$ were grown for $16-18 \mathrm{~h}$ in GC broth at $37^{\circ} \mathrm{C}$ with $3.5 \% \mathrm{CO}_{2}$ (Morse \& Bartenstein, 1974). The increased $\mathrm{CO}_{2}$ atmosphere was achieved by supplementation with $10 \mathrm{ml} 4 \cdot 3 \%$ sodium bicarbonate per litre of broth. The following antibiotic concentrations were used for growth of mutants when appropriate: $5 \mu \mathrm{g}$ tetracycline $\mathrm{ml}^{-1}$ or $60 \mu \mathrm{g}$ spectinomycin $\mathrm{ml}^{-1}$.

Preparation of total membranes. To prepare total membranes, strains were grown in $1 \mathrm{l} \mathrm{GC}$ broth for $16-18 \mathrm{~h}$ in an environmental shaker at $37^{\circ} \mathrm{C}$ and 200 r.p.m. Cells were collected by centrifugation at $11000 \mathrm{~g}$ by using a JA-14 rotor (Beckman) and the total membranes were extracted by using the method of Clark et al. (1987). All glassware was baked at $180^{\circ} \mathrm{C}$ and plasticware was washed in chloroform, then air-dried. In brief, the cell pellet was resuspended in $30 \mathrm{ml}$ $50 \mathrm{mM}$ Tris buffer $(\mathrm{pH} 8 \cdot 0)$, transferred to $50 \mathrm{ml}$ Oak Ridge tubes and collected in a pellet by centrifugation in a JA-17 rotor (Beckman) at $13000 \mathrm{~g}$ for $15 \mathrm{~min}$ at $4^{\circ} \mathrm{C}$. The supernatant was discarded and the cells washed again in $10 \mathrm{ml}$ of the same buffer. The cells were lysed by suspension in $2 \mathrm{ml}$ lysis buffer (50 mM Tris buffer, pH 8.0), $1 \mathrm{mM}$ EDTA, $20 \%$ sucrose and $1 \mathrm{mg}$ lysozyme $\mathrm{ml}^{-1}$ ) and two freeze-thaw cycles using a dry-ice ethanol bath and a room temperature water bath. After the last thaw, $20 \mathrm{ml} 50 \mathrm{mM}$ Tris buffer $(\mathrm{pH} 8 \cdot 0)$ was added and the mixture was thoroughly vortexed. The lysis mixture was sonicated in an ice bath three times $(30 \mathrm{~s}$ burst, 30 s rest) using a Virtis Virsonic 300 with a micro-tip at setting 5 . The sonicated cells were incubated on ice for $10 \mathrm{~min}$. The cellular debris was pelleted from the lysis mixture by 15 min centrifugation at $10000 \mathrm{~g}$ in a JA-17 rotor (Beckman) at $4{ }^{\circ} \mathrm{C}$. The supernatant was transferred to a clean tube and centrifuged again using the same conditions. This step was repeated twice more. The supernatant containing the membranes was loaded into preweighed polyallomer tubes, balanced in an SW28 rotor (Beckman) and ultracentrifuged at $100000 \mathrm{~g}$ for $1.5 \mathrm{~h}$ at $4{ }^{\circ} \mathrm{C}$. The supernatant was carefully drained and the translucent pellet, which contained total membranes, was weighed, then stored at $-70{ }^{\circ} \mathrm{C}$.

Extraction of phospholipids. The phospholipids were extracted from total membranes isolated from each strain using a modified method of Radin (1969). Glassware was rinsed with chloroform, then air-dried and Teflon-lined caps were used to prevent contamination with plastics. The membranes were suspended in the polyallomer tubes by the addition of solvent ( 2 vols chloroform to 1 vol. methanol) in a 17:1 (v/w) ratio of solvent to pellet and stirred constantly using micro-stir bars for $30 \mathrm{~min}$ at room temperature. The suspension was transferred to Corex glass tubes and the debris was collected by 15 min centrifugation at $10000 \mathrm{~g}$ in a JA-17 rotor (Beckman) at $4{ }^{\circ} \mathrm{C}$. The supernatant was collected and the pellet was again extracted with solvent as before. The two supernatants were combined and 2 vols Folch upper phase reagent (chloroform/methanol/water containing $0.74 \%$ potassium chloride; $3: 48: 47$, by vol.) was added. The mixture was briefly vortexed to form a single phase. The phases were separated by low speed $1 \mathrm{~min}$ centrifugation in a clinical centrifuge. The upper phase and the precipitate at the interface were discarded. The lower phase was extracted with the Folch 
Table 1. Meningococcal and gonococcal strains used in this study

\begin{tabular}{|c|c|c|c|}
\hline Strain & Genotype & Phenotype & Reference \\
\hline \multicolumn{4}{|l|}{ Wild-type isolates } \\
\hline N. meningitidis $\mathrm{NMB}$ & Wild-type & Serogroup B & Stephens et al. (1991) \\
\hline N. meningitidis F8229 & Wild-type & Serogroup A & Swartley et al. (1998) \\
\hline N. meningitidis F8239 & Wild-type & Serogroup A & Swartley et al. (1998) \\
\hline N. meningitidis 6940 & Wild-type & Serogroup B & Zollinger \& Mandrell (1977) \\
\hline N. gonorrhoeae FA 1090 & Wild-type & & Dempsey \& Cannon (1994) \\
\hline \multicolumn{4}{|l|}{ LOS mutants } \\
\hline N. meningitidis $\mathrm{M} 7$ & NMBsynX:: Tn916 & $\mathrm{cap}^{-}, \mathrm{LOS}^{+}$ & Stephens et al. (1994); Swartley \& Stephens (1994) \\
\hline N. meningitidis SS3 & NMBgalE:: Tn916 & $\operatorname{cap}^{+}, \mathrm{LOS}^{-}$ & Stephens et al. (1994); Lee et al. (1995) \\
\hline N. meningitidis CMK2 & $\mathrm{NMB} \lg t F:: a p h A-3$ & $\mathrm{cap}^{+}, \mathrm{LOS}^{-}$ & Kahler et al. (1996a) \\
\hline N. meningitidis $\mathrm{R} 6$ & NMBpgm:: Tn916 & $\mathrm{cap}^{+}, \mathrm{LOS}^{-}$ & Zhou et al. (1994) \\
\hline N. meningitidis CMK1 & $\mathrm{NMB} r f a K:: \Omega$ & $\mathrm{cap}^{+}, \mathrm{LOS}^{-}$ & Kahler et al. (1996b) \\
\hline N. meningitidis 469 & NMBnlaBgmhx::Tn916 & $\mathrm{cap}^{+}, \mathrm{LOS}^{-}$ & Shih et al. (1998) \\
\hline
\end{tabular}

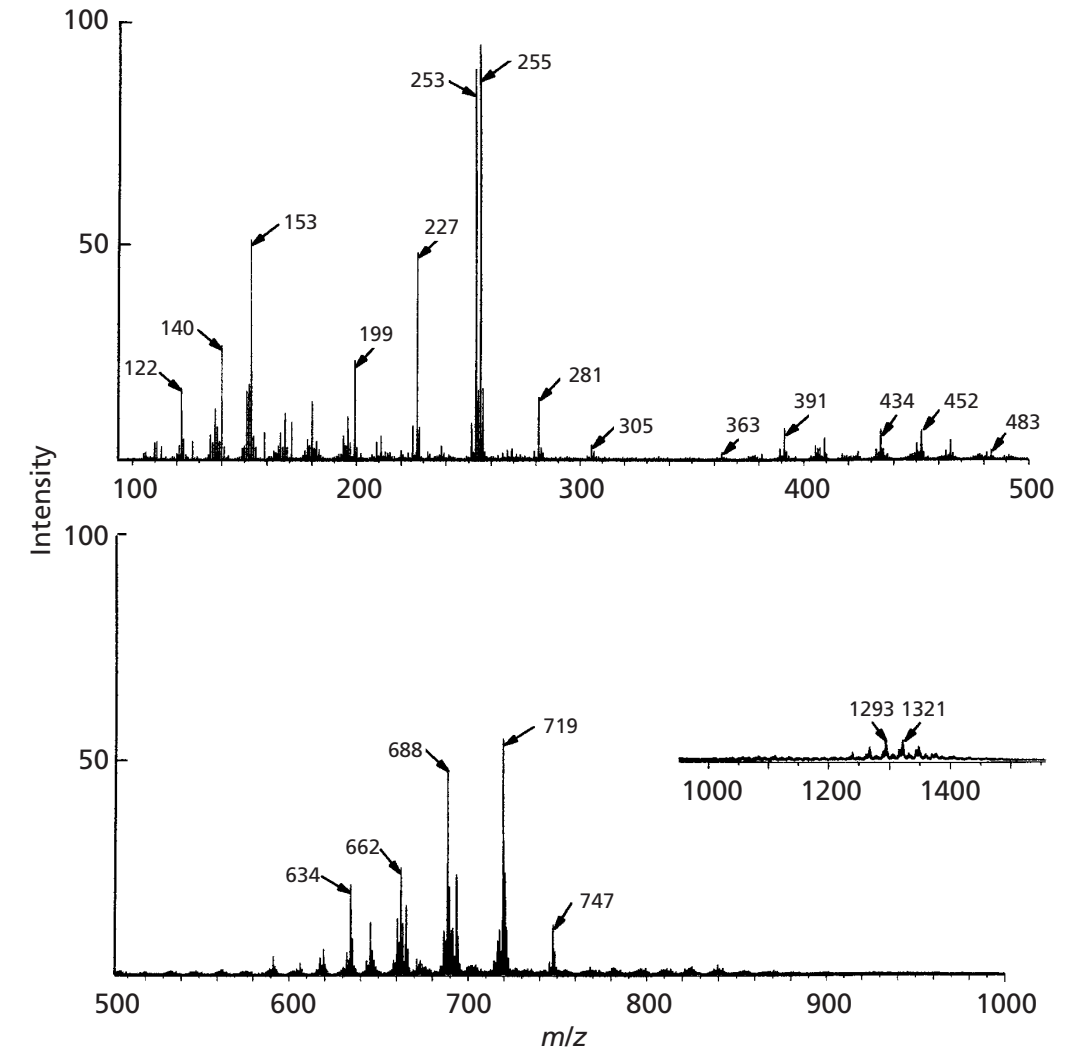

Fig. 1. $F A B$ mass spectrum for phospholipids of $N$. meningitidis NMB. See Tables 2 and 3 for peak identities. upper phase reagent at least three more times or until there was no precipitate at the interface. After the final extraction, the lower organic phase was transferred to a glass vial and the solvent evaporated under a stream of nitrogen. The dried phospholipids were stored at $-70{ }^{\circ} \mathrm{C}$ under a nitrogen atmosphere.

Fatty acid analysis. Total fatty acids were released by methanolysis of phospholipid with methanolic $1 \mathrm{M} \mathrm{HCl}$ at $80{ }^{\circ} \mathrm{C}$ for $4 \mathrm{~h}$ and were trimethylsilylated. The resulting fatty acid methyl esters were analysed by GLC-MS (York et al., 1985). Trimethylsilylation allows one to observe any hydroxy fatty acyl residues, if present. The double bond location of unsaturated fatty acids was determined by the preparation and GLC-MS analysis of dimethyl disulfide fatty acid methyl esters as described by Yruela et al. (1990).

MS. Fast atom bombardment (FAB)-MS was performed in negative-ion mode with a JEOL SX/SX 102A tandem mass spectrometer, which was operated at $10 \mathrm{kV}$ accelerating potential. Ions were produced by FAB with xenon, using a JEOL FAB gun operated at $6 \mathrm{kV}$ in a conventional FAB ion source. Spectra acquired for the first MS are averaged profile data of three scans as recorded by a JEOL XMS data system. 


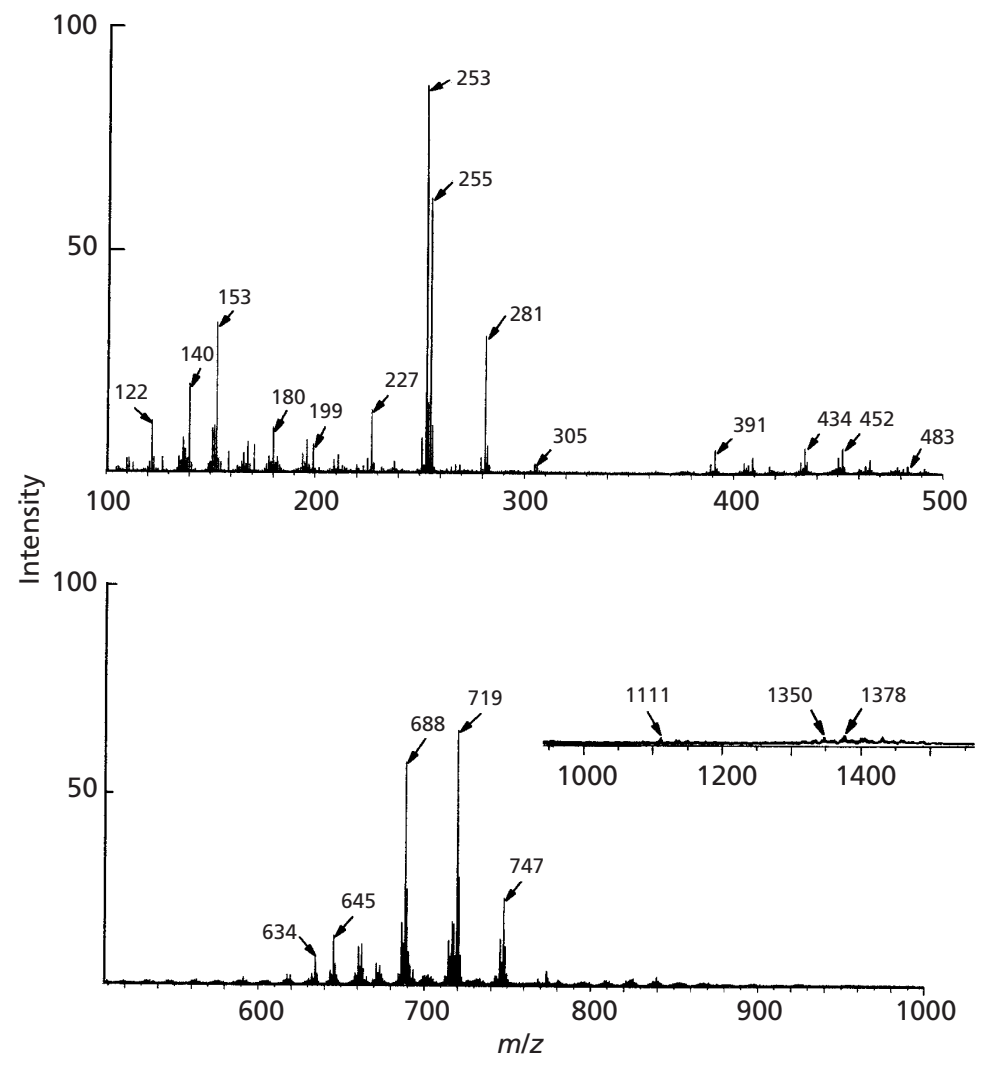

Fig. 2. $F A B$ mass spectrum for phospholipids of $N$. gonorrhoeae FA 1090. See Tables 2, 3 and 4 for peak identities.
These spectra were acquired from $100-2000 \mathrm{~m} / z$ at a rate that would scan the mass range from 0 to 2500 in $1 \mathrm{~min}$. A filtering rate of $100 \mathrm{~Hz}$ was used in acquiring these spectra. The samples were dissolved in chloroform/methanol $(2: 1, \mathrm{v} / \mathrm{v})$ solution and $1 \mu \mathrm{l}$ aliquots were mixed with an equal volume of the FAB matrix, $m$-nitrobenzyl alcohol, on an MS probe tip. After permitting solvent evaporation, the probe was placed into the sample port of the mass spectrometer. The MS/MS spectrum was obtained by using a linked scan $(B / E$ constant $)$ at a rate that would scan the mass range from 5 to 2400 in 1 min with a $300 \mathrm{~Hz}$ filter.

Quantification of phospholipids by FAB-MS. Dipalmitoyl PE, PG and phosphatidic acid (PA) were purchased from Sigma. Two series of $1 \mathrm{ml}$ solutions of these phospholipids were prepared. One series consisted of four different solutions varying in both PE and PG $(10,30,60$ and $90 \mu \mathrm{g})$ but with each containing a constant $100 \mu \mathrm{g}$ amount of PA as an internal standard. The second series varied in both PA and PG $(10,30$, 60 and $90 \mu \mathrm{g}$ ) with a constant $100 \mu \mathrm{g}$ of PE as an internal standard. Each solution was analysed by FAB-MS as described above. The data were used to (a) determine if the intensity of the molecular ion for each phospholipid was proportional to the amount of that phospholipid, and (b) determine the FABMS response of PE relative to PG and of PA relative to PG. Analysis of the first series of solutions allowed the correlation of the molecular ion intensity with mass for both PG and PE, and also allowed the calculation of the FAB-MS response factor of PE relative to PG. The second series of solutions allowed such correlation for both PA and PG, and also the calculation of the FAB-MS response factor of PA relative to PG. Using these normalized response factors, the relative amounts of the various phospholipids for each membrane preparation were calculated, assuming that all of the various PE, PG and PA molecules have the same, or very similar, FAB-
MS responses to those of the respective dipalmitoyl PE, PG and PA standards. This approach overcomes the discrepancies in phospholipid quantification that were noted by Smith et al. (1995) where a comparison of MS techniques and conventional methods of analysis were shown to disagree.

\section{RESULTS}

The genotypes and phenotypes of the N. meningitidis and $N$. gonorrhoeae strains and mutants used for the analysis of total membrane phospholipids are shown in Table 1. The composition of membrane phospholipid molecules was determined by FAB-MS performed in negative-ion mode. The FAB-MS spectra for the phospholipids from N. meningitidis $\mathrm{NMB}$ and $N$. gonorrhoeae FA 1090 are shown in Figs 1 and 2, respectively. The spectra of the phospholipids from the other strains are not shown but the results are included in Table 4 and are discussed below.

\section{Membrane fatty acid compositions}

The fragment ions of $\mathrm{m} / z$ values from 199 to 300 represent fatty acid carboxylate anions. The fatty acids found in the various phospholipids from both wild-type and mutant strains are shown in Table 2. The most intense ions were: $m / z 253$, C16:1; 255, C16:0; and 227, C14:0. In addition, the following less-intense ions were also observed: 199, C12:0; 225, C14:1; 269, C17:0; 281, C18:1; 283, C18:0. These phospholipidderived carboxylate fragment ions were as reported by Drucker et al. (1995). 
Table 2. Carboxylate molecular species of the neisserial phospholipids observed as anions in FAB-MS spectra

Data are expressed as percentage total carboxylate anion peak. Bold type indicates the major components present in the respective samples.

\begin{tabular}{|c|c|c|c|c|c|c|c|c|c|c|c|c|}
\hline \multicolumn{2}{|c|}{ Carboxylate ion } & \multicolumn{11}{|c|}{ Relative ion intensity } \\
\hline$m / z$ & $\mathrm{ID}^{*}$ & NMB & F8229 & F8239 & 6940 & FA 1090 & M7 & SS3 & CMK2 & R6 & CMK1 & 469 \\
\hline 199 & $12: 0$ & $8 \cdot 4$ & $8 \cdot 0$ & $6 \cdot 2$ & $6 \cdot 6$ & $3 \cdot 1$ & $9 \cdot 7$ & $8 \cdot 4$ & $8 \cdot 5$ & 10 & 10 & $8 \cdot 7$ \\
\hline 225 & $14: 1$ & $3 \cdot 1$ & $2 \cdot 7$ & $2 \cdot 5$ & $3 \cdot 4$ & $1 \cdot 6$ & $2 \cdot 6$ & $2 \cdot 7$ & $2 \cdot 5$ & $2 \cdot 6$ & $2 \cdot 6$ & $2 \cdot 6$ \\
\hline 227 & $14: 0$ & 17 & 18 & 20 & 12 & $6 \cdot 7$ & 20 & 18 & 20 & 20 & 13 & 16 \\
\hline 251 & $16: 2$ & $3 \cdot 2$ & $2 \cdot 4$ & $1 \cdot 9$ & $5 \cdot 2$ & $4 \cdot 0$ & $2 \cdot 0$ & $2 \cdot 9$ & $2 \cdot 2$ & $2 \cdot 1$ & $3 \cdot 1$ & $2 \cdot 9$ \\
\hline 253 & $16: 1$ & 30 & 29 & 25 & 35 & 42 & 24 & 29 & 27 & 25 & 31 & 30 \\
\hline 255 & $16: 0$ & 33 & 35 & 40 & 29 & 29 & 37 & 34 & 35 & 35 & 34 & 33 \\
\hline 281 & $18: 1$ & $4 \cdot 8$ & $5 \cdot 5$ & $4 \cdot 3$ & $8 \cdot 2$ & 14 & $4 \cdot 5$ & $5 \cdot 2$ & $5 \cdot 5$ & $4 \cdot 4$ & $5 \cdot 3$ & $7 \cdot 1$ \\
\hline
\end{tabular}

† 12:0, Dodecanoate; 14:1, tetradecenoate; 14:0, tetradecanoate (myristate); 16:2, hexadidecenoate; 16:1, hexadecenoate; 16:0, hexadecanoate; $18: 1$, octadecenoate.

Table 3. Fatty acid composition analysis of neisserial phospholipids

Data are expressed as percentage fatty acid methyl ester GLC total peak area. Bold type indicates the major components present in the respective samples. TR, trace.

\begin{tabular}{|c|c|c|c|c|c|c|c|c|c|c|c|}
\hline ID* & NMB & F8229 & F8239 & 6940 & FA 1090 & M7 & SS3 & CMK2 & R6 & CMK1 & 469 \\
\hline $12: 0$ & TR & TR & TR & TR & TR & TR & TR & TR & TR & TR & TR \\
\hline $14: 1$ & TR & TR & TR & TR & $\mathrm{TR}$ & TR & TR & TR & TR & $\mathrm{TR}$ & TR \\
\hline $14: 0$ & 20 & 18 & 21 & 10 & 6 & 19 & 14 & 19 & 19 & 18 & 17 \\
\hline $16: 2$ & TR & TR & TR & TR & $\mathrm{TR}$ & TR & TR & TR & TR & TR & TR \\
\hline $16: 1$ & 28 & 26 & 30 & 31 & 37 & 23 & 27 & 27 & 24 & 25 & 22 \\
\hline $16: 0$ & 47 & 49 & 43 & 44 & 41 & 52 & 52 & 47 & 51 & 50 & 54 \\
\hline $18: 1$ & 5 & 7 & 6 & 15 & 16 & 6 & 7 & 7 & 6 & 8 & 7 \\
\hline
\end{tabular}

*Fatty acids are designated as described for Table 2.

The total fatty acid composition of phospholipids from wild-type N. meningitidis and N. gonorrhoeae and meningococcal mutant strains were also analysed by methanolysis followed by trimethylsilylation and analysis by GLC-MS. The results of the GLC-MS analysis (Table 3) show that the major fatty acids observed by this method are consistent with the major fatty acids observed by FAB-MS analysis (Table 2.) The C12:0 fatty acid was observed in both the FAB-MS and GLCMS analyses, but the high volatility of its methyl ester prevented accurate quantification by the GLC-MS procedure. However, the FAB-MS spectra clearly show that C12:0 was present in the phospholipids of all meningococcal strains examined $(6 \cdot 5-10 \%)$ and a lesser amount $(3 \cdot 3 \%)$ in N. gonorrhoeae FA 1090.

The phospholipids of N. gonorrhoeae FA 1090 contained significantly less shorter-chain fatty acids (e.g. C12:0, C14:0 and C14:1) compared to the N. meningitidis strains (Figs 1 and 2, Tables 2 and 3). The phospholipids from the three $N$. meningitidis isolates,

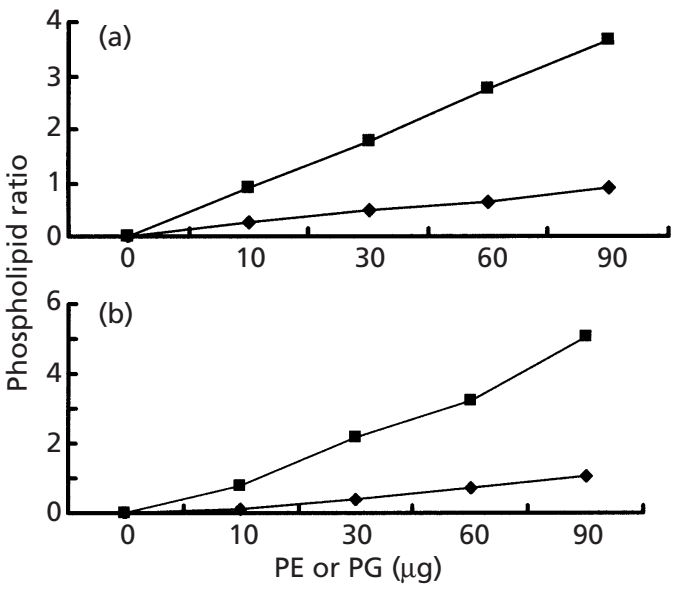

Fig. 3. Correlation of molecular ion intensity with the amount of phospholipid. (a) Variation in PG ( $\boldsymbol{\square})$ and PA ( $\bullet$ ) while holding PE at a constant level $(100 \mu \mathrm{g})$. (b) Variation of PG ( $\mathbf{\square})$ and PE $(\diamond)$ while holding PA constant $(100 \mu \mathrm{g})$. 
Table 4. Neisserial phospholipid content as determined by FAB-MS analysis

Data are expressed as relative mass percentage of total phospholipid. The values were corrected for the different responses of PE, PG, and PA during FAB-MS analysis, and were normalized to PG that has the highest response. The NMB values and standard errors were calculated from the analyses of three different NMB phospholipid preparations.

\begin{tabular}{|c|c|c|c|c|c|c|c|c|c|c|c|c|}
\hline \multicolumn{2}{|c|}{ Phospholipid } & \multicolumn{11}{|c|}{ Phospholipid content } \\
\hline$m / z$ & $\mathrm{ID}^{*}$ & NMB & F8229 & F8239 & 6940 & FA 1090 & M7 & SS3 & СMK2 & R6 & CMK1 & 469 \\
\hline 591 & $\operatorname{PA}(28: 0)$ & $1 \cdot 7 \pm 0 \cdot 2$ & $1 \cdot 8$ & $2 \cdot 1$ & $1 \cdot 6$ & $0 \cdot 7$ & $1 \cdot 7$ & $1 \cdot 7$ & $1 \cdot 7$ & $2 \cdot 0$ & $1 \cdot 9$ & $1 \cdot 4$ \\
\hline 617 & $\operatorname{PA}(30: 1)$ & $1 \cdot 4 \pm 0 \cdot 2$ & $1 \cdot 7$ & $2 \cdot 3$ & $2 \cdot 0$ & $0 \cdot 8$ & $1 \cdot 3$ & $1 \cdot 3$ & $1 \cdot 4$ & $1 \cdot 6$ & $1 \cdot 7$ & $1 \cdot 1$ \\
\hline 619 & $\operatorname{PA}(30: 0)$ & $2 \cdot 0 \pm 0 \cdot 2$ & $2 \cdot 1$ & $3 \cdot 1$ & $1 \cdot 8$ & $0 \cdot 8$ & $2 \cdot 4$ & $2 \cdot 0$ & $2 \cdot 2$ & $2 \cdot 4$ & $2 \cdot 5$ & $1 \cdot 6$ \\
\hline 645 & $\operatorname{PA}(32: 1)$ & $3 \cdot 7 \pm 0 \cdot 2$ & $4 \cdot 2$ & $5 \cdot 6$ & $4 \cdot 4$ & $4 \cdot 0$ & $3 \cdot 4$ & $3 \cdot 6$ & $4 \cdot 0$ & $3 \cdot 9$ & $3 \cdot 5$ & $2 \cdot 9$ \\
\hline \multirow[t]{2}{*}{647} & $\operatorname{PA}(32: 0)$ & $1 \cdot 2 \pm 0 \cdot 1$ & $1 \cdot 2$ & $2 \cdot 1$ & $1 \cdot 4$ & $0 \cdot 8$ & $1 \cdot 3$ & $1 \cdot 2$ & $1 \cdot 2$ & $1 \cdot 1$ & $1 \cdot 8$ & $0 \cdot 9$ \\
\hline & Total PA & $10 \cdot 0 \pm 1 \cdot 0$ & $11 \cdot 0$ & $15 \cdot 2$ & $11 \cdot 2$ & $7 \cdot 1$ & $10 \cdot 1$ & $9 \cdot 8$ & $10 \cdot 5$ & $11 \cdot 0$ & $11 \cdot 4$ & $7 \cdot 9$ \\
\hline 632 & $\operatorname{PE}(28: 1)$ & $2 \cdot 8 \pm 0 \cdot 2$ & $2 \cdot 8$ & $2 \cdot 7$ & $4 \cdot 2$ & $1 \cdot 3$ & $2 \cdot 5$ & $2 \cdot 9$ & $2 \cdot 1$ & $2 \cdot 7$ & $3 \cdot 9$ & $3 \cdot 2$ \\
\hline 634 & $\operatorname{PE}(28: 0)$ & $11 \cdot 2 \pm 3 \cdot 1$ & $10 \cdot 9$ & $8 \cdot 4$ & $5 \cdot 8$ & $3 \cdot 7$ & $12 \cdot 1$ & $10 \cdot 6$ & $10 \cdot 8$ & $12 \cdot 2$ & $9 \cdot 8$ & $10 \cdot 5$ \\
\hline 660 & $\operatorname{PE}(30: 1)$ & $6 \cdot 4 \pm 1 \cdot 1$ & $7 \cdot 4$ & $7 \cdot 3$ & $7 \cdot 1$ & $4 \cdot 9$ & $5 \cdot 8$ & $5 \cdot 8$ & $5 \cdot 9$ & $6 \cdot 3$ & $6 \cdot 6$ & $6 \cdot 6$ \\
\hline 662 & $\operatorname{PE}(30: 0)$ & $12 \cdot 7 \pm 3 \cdot 1$ & $12 \cdot 7$ & $12 \cdot 5$ & $5 \cdot 4$ & $5 \cdot 2$ & $16 \cdot 9$ & $11 \cdot 1$ & $14 \cdot 7$ & $13 \cdot 8$ & $12 \cdot 7$ & $11 \cdot 6$ \\
\hline 686 & $\operatorname{PE}(32: 2)$ & $4 \cdot 6 \pm 0 \cdot 4$ & $4 \cdot 9$ & $5 \cdot 4$ & $9 \cdot 1$ & $7 \cdot 9$ & $3 \cdot 6$ & $4 \cdot 4$ & $4 \cdot 1$ & $4 \cdot 2$ & $4 \cdot 3$ & $5 \cdot 3$ \\
\hline 688 & $\operatorname{PE}(32: 1)$ & $20 \cdot 7 \pm 3 \cdot 3$ & $23 \cdot 7$ & $22 \cdot 2$ & $15 \cdot 6$ & $28 \cdot 3$ & $21 \cdot 3$ & $18 \cdot 4$ & $24 \cdot 2$ & $21 \cdot 6$ & $15 \cdot 0$ & $22 \cdot 4$ \\
\hline 690 & $\operatorname{PE}(32: 0)$ & $4 \cdot 8 \pm 0 \cdot 6$ & $5 \cdot 7$ & $7 \cdot 1$ & $4 \cdot 0$ & $4 \cdot 2$ & $6 \cdot 6$ & $4 \cdot 4$ & $5 \cdot 3$ & $4 \cdot 5$ & $7 \cdot 1$ & $5 \cdot 3$ \\
\hline 714 & $\operatorname{PE}(34: 2)$ & $1 \cdot 5 \pm 0 \cdot 2$ & $2 \cdot 2$ & $2 \cdot 8$ & $3 \cdot 8$ & $5 \cdot 7$ & $1 \cdot 6$ & $1 \cdot 5$ & $1 \cdot 8$ & $1 \cdot 7$ & $3 \cdot 4$ & $2 \cdot 1$ \\
\hline 716 & $\operatorname{PE}(34: 1)$ & $3 \cdot 5 \pm 0 \cdot 4$ & $4 \cdot 7$ & $4 \cdot 0$ & $4 \cdot 7$ & $8 \cdot 2$ & $4 \cdot 3$ & $3 \cdot 5$ & $5 \cdot 1$ & $4 \cdot 2$ & $5 \cdot 3$ & $4 \cdot 8$ \\
\hline \multirow[t]{2}{*}{718} & $\operatorname{PE}(34: 0)$ & $2 \cdot 6 \pm 0 \cdot 9$ & $1 \cdot 6$ & $1 \cdot 3$ & $5 \cdot 3$ & $3 \cdot 8$ & $1 \cdot 5$ & $3 \cdot 3$ & $1 \cdot 7$ & $1 \cdot 7$ & $3 \cdot 4$ & $2 \cdot 4$ \\
\hline & Total PE & $70 \cdot 8 \pm 10 \cdot 7$ & $76 \cdot 6$ & $73 \cdot 7$ & $65 \cdot 0$ & $73 \cdot 2$ & $76 \cdot 2$ & $65 \cdot 9$ & $75 \cdot 7$ & $72 \cdot 9$ & $71 \cdot 5$ & $74 \cdot 2$ \\
\hline 661 & $\operatorname{PG}(28: 2)$ & $0 \cdot 9 \pm 0 \cdot 1$ & $0 \cdot 9$ & $1 \cdot 0$ & $1 \cdot 0$ & $0 \cdot 6$ & $0 \cdot 8$ & $0 \cdot 9$ & $0 \cdot 8$ & $0 \cdot 8$ & $0 \cdot 9$ & $0 \cdot 8$ \\
\hline 663 & $\operatorname{PG}(28: 1)$ & $1 \cdot 5 \pm 0 \cdot 2$ & $1 \cdot 3$ & $1 \cdot 3$ & $1 \cdot 1$ & $0 \cdot 5$ & $1 \cdot 7$ & $1 \cdot 5$ & $1 \cdot 5$ & $1 \cdot 5$ & $1 \cdot 5$ & $1 \cdot 3$ \\
\hline 665 & $\operatorname{PG}(28: 0)$ & $2 \cdot 0 \pm 0 \cdot 5$ & $0 \cdot 9$ & $0 \cdot 6$ & $1 \cdot 7$ & $0 \cdot 2$ & $1 \cdot 5$ & $3 \cdot 0$ & $1 \cdot 2$ & $1 \cdot 9$ & $1 \cdot 6$ & $1 \cdot 7$ \\
\hline 689 & $\operatorname{PG}(30: 2)$ & $2 \cdot 2 \pm 0 \cdot 3$ & $2 \cdot 5$ & $2 \cdot 4$ & $1 \cdot 9$ & $2 \cdot 9$ & $2 \cdot 2$ & $2 \cdot 1$ & $2 \cdot 5$ & $2 \cdot 2$ & $1 \cdot 7$ & $2 \cdot 4$ \\
\hline 691 & $\operatorname{PG}(30: 1)$ & $1 \cdot 3 \pm 0 \cdot 3$ & $0 \cdot 9$ & $0 \cdot 9$ & $2 \cdot 0$ & $0 \cdot 6$ & $0 \cdot 9$ & $1 \cdot 5$ & $0 \cdot 8$ & $0 \cdot 9$ & $1 \cdot 2$ & $1 \cdot 1$ \\
\hline 693 & $\operatorname{PG}(30: 0)$ & $2 \cdot 5 \pm 0 \cdot 7$ & $1 \cdot 2$ & $0 \cdot 9$ & $2 \cdot 2$ & $0 \cdot 5$ & $1 \cdot 8$ & $3 \cdot 6$ & $1 \cdot 5$ & $2 \cdot 1$ & $2 \cdot 1$ & 1.9 \\
\hline 717 & PG $(32: 2)$ & $1 \cdot 1 \pm 0 \cdot 3$ & $0 \cdot 8$ & $0 \cdot 7$ & $2 \cdot 5$ & $1 \cdot 9$ & $0 \cdot 7$ & $1 \cdot 4$ & $0 \cdot 9$ & $0 \cdot 8$ & $1 \cdot 3$ & $1 \cdot 1$ \\
\hline 719 & $\operatorname{PG}(32: 1)$ & $5 \cdot 5 \pm 2 \cdot 1$ & $2 \cdot 5$ & $1 \cdot 5$ & $7 \cdot 0$ & $7 \cdot 8$ & $2 \cdot 5$ & $7 \cdot 2$ & $3 \cdot 1$ & $3 \cdot 8$ & $3 \cdot 9$ & 4.9 \\
\hline 721 & PG $(32: 0)$ & $1 \cdot 1 \pm 0 \cdot 4$ & $0 \cdot 7$ & $0 \cdot 8$ & $1 \cdot 4$ & $0 \cdot 9$ & $0 \cdot 8$ & $1 \cdot 4$ & $0 \cdot 7$ & $0 \cdot 8$ & $1 \cdot 5$ & $1 \cdot 0$ \\
\hline 745 & $\operatorname{PG}(34: 2)$ & $0 \cdot 4 \pm 0 \cdot 2$ & $0 \cdot 2$ & $0 \cdot 2$ & $1 \cdot 1$ & $1 \cdot 4$ & $0 \cdot 2$ & $0 \cdot 4$ & $0 \cdot 2$ & $0 \cdot 3$ & $0 \cdot 5$ & $0 \cdot 4$ \\
\hline \multirow[t]{2}{*}{747} & $\operatorname{PG}(34: 1)$ & $1 \cdot 1 \pm 0 \cdot 4$ & $0 \cdot 7$ & $0 \cdot 5$ & $1 \cdot 9$ & $2 \cdot 6$ & $0 \cdot 7$ & $1 \cdot 4$ & $0 \cdot 8$ & $0 \cdot 9$ & $0 \cdot 8$ & $1 \cdot 4$ \\
\hline & Total PG & $19 \cdot 6 \pm 4 \cdot 5$ & $12 \cdot 6$ & $10 \cdot 8$ & $23 \cdot 8$ & $19 \cdot 9$ & $13 \cdot 8$ & $24 \cdot 4$ & $14 \cdot 0$ & $16 \cdot 0$ & $17 \cdot 0$ & $18 \cdot 0$ \\
\hline
\end{tabular}

*Example of abbreviations for phospholipids: $\mathrm{PE}(28: 0)$ indicates a phosphatidylethanolamine in which the total number of carbons for both fatty acyl residues is 28 .

NMB, F8229 and F8239, had similar fatty acid profiles. However, N. meningitidis 6940 had a fatty acid profile resembling that of N. gonorrhoeae FA 1090. Both 6940 and FA 1090 contained 1.5-3-fold more C18:1 and a corresponding 1.5-3-fold decrease of C14:0 when compared to the meningococcal isolates NMB, F8229 and F8239. No significant differences were observed in the fatty acid profiles of the capsule and LOS mutants compared to that of the parent strain, NMB.

\section{Phospholipid compositions}

The relative mass percentage of each phospholipid was determined from the molecular ion intensities of the various phospholipid molecules. To determine if ion intensity was proportional to the amount of a particular phospholipid, the molecular ion intensities were measured for known amounts of dipalmitoyl PA, PG and PE by varying the level of two of the phospholipids while holding the amount of the third phospholipid constant. Under these conditions, the phospholipid that was held constant acted as an internal standard. In the first series, PG and PA were varied while PE was the constant internal standard. Fig. 3(a) shows that both the PG/PE and PA/PE molecular ion intensity ratios were proportional to the amount of $\mathrm{PG}$ and $\mathrm{PA}$, respectively. Likewise, Fig. 3(b) shows that the PG/PA and PE/PA molecular ion intensity ratios were proportional to the amounts of PG and PE, respectively. By calculating the $(\mathrm{PA} / \mathrm{PE}) /(\mathrm{PG} / \mathrm{PE})$ and $(\mathrm{PE} / \mathrm{PA}) /(\mathrm{PG} / \mathrm{PA})$ values for each concentration from Fig. 3(a) and (b), respectively, the response of PA to PG and of PE to PG were determined to be $0 \cdot 37 \pm 0 \cdot 06$ and $0 \cdot 24 \pm 0 \cdot 04$, respectively. Thus, the amount of each PA molecule can be 

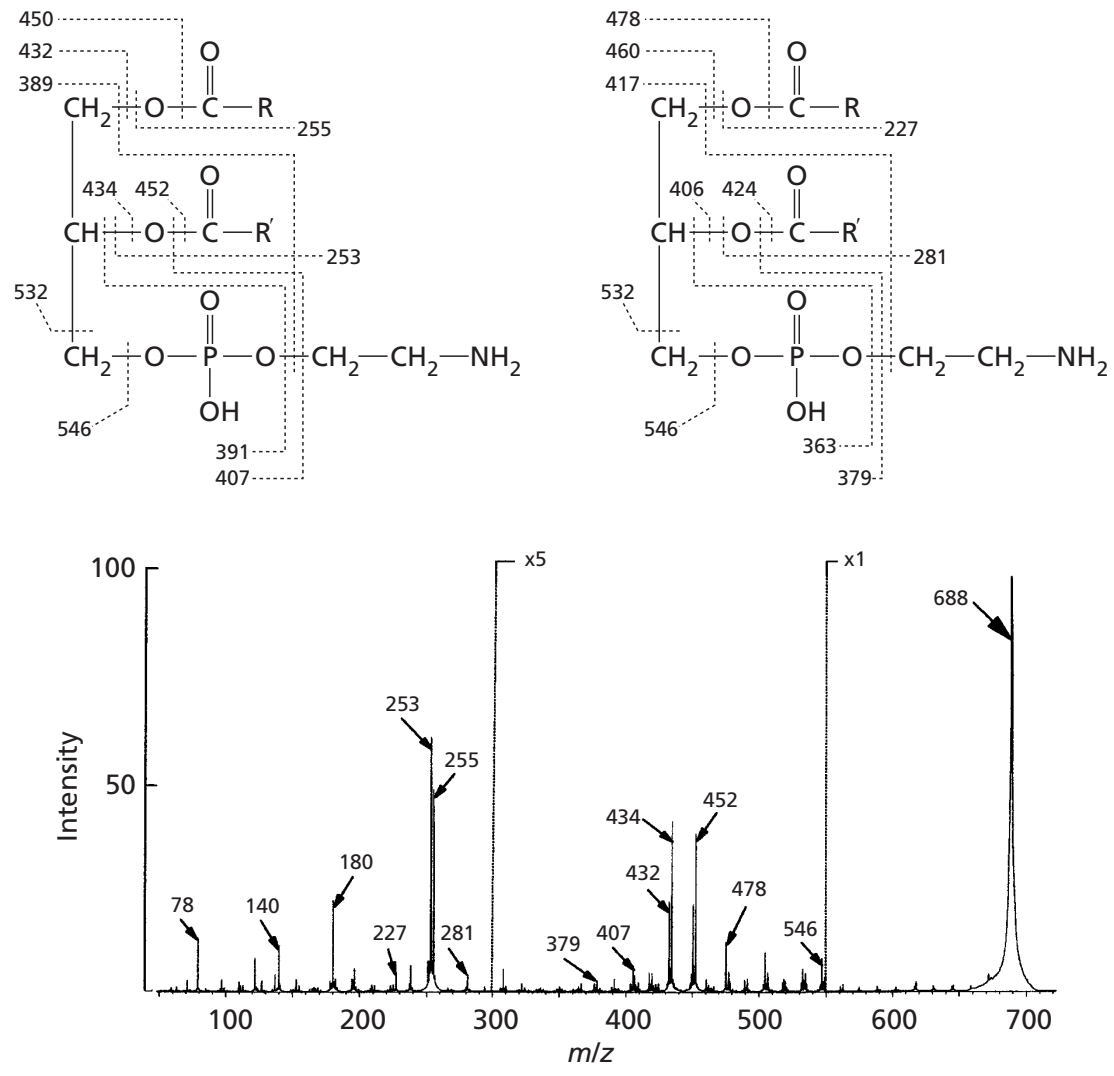

Fig. 4. Tandem MS/MS spectrum of the $\mathrm{m} / \mathrm{z}$ 688 ion in the FAB-MS of $N$. meningitidis NMB phospholipid. The top shows the phospholipid structures and the expected fragmentation pattern for those structures.

normalized to PG by dividing its molecular ion intensity by 0.37 and the amount of each PE molecule can be normalized to PG by dividing its molecular ion intensity by $0 \cdot 24$.

Using the approach outlined above, the relative amounts of the various phospholipids for each membrane preparation were determined and are shown in Table 4. In all of the preparations, the amount of total PE was greatest, varying from 65 to $77 \%$, followed by PG (14-20\%) and then PA $(8-11 \%)$. The standard error observed in total PE, PG and PA values for three different NMB preparations (see Table 4) suggests that there are significant differences in the levels of the various phospholipids among the $N$. meningitidis strains and the N. gonorrhoeae strain. That PE was the most abundant class of phospholipid in meningococci and gonococci is consistent with previous results (see review by Wilkinson, 1988). However, previous studies also indicated that $N$. gonorrhoeae membranes contain up to $20 \%$ DPG (see review by Wilkinson, 1988). The FAB-MS analysis shown in Figs 1 and 2 indicated only trace levels of DPG present in both the meningococcal and gonococcal isolates that we examined. In the case of N. meningitidis NMB the ions at $m / z 1321$ and 1293 probably represent DPG $(\mathrm{C} 62: 1)$ and DPG $(\mathrm{C} 60: 1)$, respectively. In the case of $N$. gonorrhoeae, ions of very weak intensities are observed at about $m / z 1350$ and 1378 (there may be more variability in these values due to their low intensities), which may represent DPG(C64:1) and $\operatorname{DPG}(66: 1)$. It is possible that a portion of the ions attributed to PA could be due to fragmentation of DPG. However, it is unlikely that a significant percentage of the PA ions is due to such fragmentation since (i) it has been shown that FAB-MS analysis of DPG results in a molecular ion that has an intensity about fivefold greater than any of the fragment ions that could be attributed to PA (Jensen et al., 1987), and (ii) our data show DPG ions of only very weak intensities. In addition, the FAB-MS spectra (see Figs 1 and 2) all show lower intensity ions at $m / z 391,409,434,452$ and 465 . These ions could arise by molecular fragmentation of PE or PG molecules as described by Drucker et al. (1995), or may be due, in part, to the presence of lysophospholipid molecules.

A major difference between neisserial phospholipids and those from Gram-negative enteric bacterial species is the abundance of the short-chain fatty acyl substituents in the former (see review by Wilkinson, 1988), a result confirmed by this study. This increase in shorter-chain fatty acyl groups was reflected in the proportion of PE and PG molecules which contain C12:0, C14:0 or C14:1. The relative percentage of total PE and total PG which contain shorter-chain fatty acyl groups (i.e. fatty acyl chains in which the number of carbons for both fatty acids total 30 or less) varies from 21 to $47 \%$ for PE and from 24 to $66 \%$ for PG, while those same values for E. coli are $8 \cdot 1$ and $4 \cdot 4 \%$ for PE and PG, respectively (calculated from the phospholipid data reported for $E$. coli in the review by Wilkinson, 1988). It is clear from these results that, in comparison to E. coli, all of the neisserial phospholipids are greatly enriched with 
Table 5. The ratios of the various isobaric phospholipid molecules and the position of the fatty acyl substituents for each molecular species

\begin{tabular}{|c|c|c|c|c|}
\hline \multirow[t]{2}{*}{ Molecular ion* } & \multicolumn{4}{|c|}{ Position of the fatty acyl substituents } \\
\hline & $s n-1$ & $s n-2$ & Phospholipid & $A: B$ ratio \\
\hline $719-\mathrm{A}$ & $\mathrm{C} 16: 0$ & $\mathrm{C} 16: 1$ & PG & $4: 1$ \\
\hline $719-B$ & $\mathrm{C} 14: 0$ & $\mathrm{C} 18: 1$ & PG & \\
\hline $688-\mathrm{A}$ & $\mathrm{C} 16: 0$ & $\mathrm{C} 16: 1$ & PE & $6: 1$ \\
\hline $688-\mathrm{B}$ & C14:0 & C18:1 & PE & \\
\hline 662 & $\mathrm{C} 16: 0$ & $\mathrm{C} 14: 0$ & $\mathrm{PE}$ & \\
\hline 693-A & $\mathrm{C} 13: 0$ & $\mathrm{C} 17: 0$ & PG & $1 \cdot 2: 1$ \\
\hline $693-B$ & $\mathrm{C} 16: 0$ & $\mathrm{C} 14: 0$ & PG & \\
\hline $634-\mathrm{A}$ & $\mathrm{C} 16: 0$ & C12:0 & $\mathrm{PE}$ & $1 \cdot 3: 1$ \\
\hline $634-B$ & $\mathrm{C} 14: 0$ & C14:0 & PE & \\
\hline $665-\mathrm{A}$ & $\mathrm{C} 16: 0$ & $\mathrm{C} 12: 0$ & PG & $9: 1$ \\
\hline $665-B$ & $\mathrm{C} 14: 0$ & $\mathrm{C} 14: 0$ & PG & \\
\hline
\end{tabular}

*A and B represent two molecular species of the same mass, e.g. 719-A and 719-B are two different PG molecules having the same [M-H] value of $m / z 719$.

molecules that contain shorter-chain fatty acyl substituents.

\section{Isobaric phospholipid molecules and the positions of fatty acyl substituents}

The structures of the various phospholipids were further characterized via tandem MS/MS analysis of single molecular ions which resulted in characteristic formation of fragment ions during collision-induced dissociation (CID). In addition, the relative intensities of the acyl carboxylate fragment ions from tandem MS/MS analysis indicate their positions in the phospholipid (Jensen et al., 1987; Cole \& Enke, 1991); i.e. at the $s n-1$ or $s n-2$ positions. The carboxylate fragment ion from the fatty acyl component at $s n$ - 2 will form in preference to that at the $s n-1$ position and will, therefore, have the greatest intensity (Jensen et al., 1987; Cole \& Enke, 1991). Fig. 4 shows the fragment ion spectrum obtained by tandem MS/MS analysis of a phospholipid from strain NMB. The structural basis for these assignments is also given in Fig. 4. These data are consistent with the $m / z 688$ ion being due to two isobaric PE molecules; one major PE component with C16:1 $(m / z 253)$ and C16:0 $(m / z 255)$ as the acyl substituents and a second minor component with C18:1 $(\mathrm{m} / z 281)$ and C14:0 $(\mathrm{m} / z 227)$ as the acyl substituents. Similarly, tandem MS/MS analysis of $m / z 719$ (spectrum not shown) suggests that this ion is due to two isobaric PG structures, the major component with C16:0 and C16:1 as the acyl substituents and a minor component substituted with $\mathrm{C} 14: 0$ and C18:1. The MS/MS spectra of other major phospholipids having masses of 693, 665 and 635 were also obtained and the resulting data indicate that they have the structures given in Table 5. According to these results, every phospholipid examined by tandem MS/MS contained a saturated fatty acyl substituent at the $s n-1$ position and contained either a saturated or unsaturated fatty acyl substituent at the $s n-2$ position.

\section{DISCUSSION}

In this study, FAB-MS, GLC-MS and tandem MS/MS techniques were used to analyse the structures of the phospholipids from four isolates of $N$. meningitidis and one isolate of $N$. gonorrhoeae, as well as from six LOS and capsule mutants of N. meningitidis NMB. The membrane preparations were extracted from stationaryphase cultures grown under conditions similar to those in all earlier studies of neisserial phospholipids (Wilkinson, 1988; Sud \& Feingold, 1976; Wolf-Watz et al., 1975; Senff et al., 1976; Guymon et al., 1978; Lewis et al., 1968; Moss et al., 1970). These earlier studies, most performed by using TLC, found that the fatty acyl groups of the phospholipids of N. gonorrhoeae and the fatty acids from cellular lipid extracts from N. meningitidis were more heterogeneous than those reported for other bacterial species (see review by Wilkinson, 1988), including E. coli, on which the standard model for the phospholipid and anaerobic fatty acid biosynthetic pathways is based (Rock et al., 1996; Shibuya, 1992). The major phospholipids previously reported in $N$. gonorrhoeae were PE and PG, with up to $20 \%$ of total phospholipids reported as DPG. The most predominant fatty acids were C14:0, C16:0, C16:1 and C18:1 with lower, but significant levels of C12:0 (Guymon et al., 1978; Sud \& Feingold, 1976; Senff et al., 1976; WolfWatz et al., 1975; Wilkinson, 1988). Interestingly, a comparison of the results from these previous surveys indicated that the fatty acid profiles of most neisserial isolates were similar, even though cells were harvested from different growth conditions. The fatty acid profiles of bacteria from overnight broth cultures (Lewis et al., 1968), overnight plate cultures (Moss et al., 1970) or from different phases of growth (Sud \& Feingold, 1976) were all remarkably similar. This behaviour is quite different from E. coli where the expression of DPG is dependent on the growth phase of growth (Rock et al., 1996).

The results of the present study both support and are at variance with results of previous studies in gonococci. The major classes of phospholipids present in meningococci and gonococci were PE (65-77\%), followed by PG (14-24\%), confirming other work (Sud \& Feingold, 1976; Wolf-Watz et al., 1975; Senff et al., 1976; Guymon et al., 1978; Lewis et al., 1968; Moss et al., 1970). The present study also confirms that pathogenic Neisseria spp. contain significant levels of short-chain fatty acids, C12:0, C14:1 and in particular C14:0, which account for one-fifth of the total fatty acid composition of some meningococcal strains. However, in contrast to the earlier reports, we detected significant levels of PA $(7-11 \%)$ and very low levels of DPG in all strains. The reason for the contrast between our results and those previously reported is not known; however, the contrast 
in results could reflect real strain differences in phospholipid profiles or differences in the FAB-MS technique used in our work versus the TLC procedures used in the earlier work. Variability in amounts of PE, PG and PA was observed between the different $N$. meningitidis strains, including the LOS mutants of strain NMB and $N$. gonorrhoeae. The biological significance, if any, of these differences in overall phospholipid distribution requires further study, but illustrates the variability of meningococcal and gonococcal surface constituents.

Detailed structural analysis of the phospholipids of $N$. meningitidis and N. gonorrhoeae has not been previously reported (e.g. the fatty acylation patterns of the various phospholipids). The FAB-MS spectra of the phospholipid species produced by both meningococci and gonococci revealed a diverse array of acyl chains attached to each type of phospholipid head group. Tandem MS/MS was used to identify the acyl chain attachments at the $s n-1$ and $s n-2$ positions of the major phospholipids. This analysis confirmed that neisserial phospholipids contain a saturated fatty acyl substituent at $s n-1$ and either a saturated or unsaturated fatty acyl substituent at $s n$-2, verifying the diversity of these structures. The major phospholipids of E. coli have an asymmetric distribution with the $s n-1$ position of the glycerol phosphate backbone containing the saturated fatty acid C16:0, while $s n-2$ is occupied by unsaturated fatty acids C16:1 or C18:1 (Rock et al., 1996; Wilkinson, 1988). Minor phospholipids from E. coli have $\mathrm{C} 14: 0, \mathrm{C} 16: 1$ or $\mathrm{C} 18: 1$ in the $s n-1$ position (see review by Wilkinson, 1988). The predominant phospholipids of N. meningitidis NMB, PG(32:1) $(28 \%$ of total PG) and PE(32:1) (29\% of total PE), have a similar asymmetrical distribution of saturated (C16:0 or C14:0) and unsaturated $(\mathrm{C} 16: 1$ or $\mathrm{C} 18: 1)$ acyl chains at the $s n-1$ and $s n-2$ positions, respectively, of the glycerol phosphate backbone. A major difference between the neisserial phospholipids and those from E. coli, is that the former have a much greater level of short-chain fatty acid substituents. This greater diversity of shortchain fatty acyl substituents is consistent with our previous report (Shih et al., 1998) showing that strain NMB contains at least two lysophosphatidic acid (LPA) acyltransferases which catalyse the transfer from acylACP to the $s n-2$ position of the glycerol phosphate backbone. In comparison, E. coli contains only one LPA acyltransferase (Coleman, 1992).

In two of the isolates, N. meningitidis 6940 and N. gonorrhoeae FA 1090, the amount of C14:0 was significantly decreased (1.5-3-fold) with a concomitant increase in C18:1 content compared to the other strains examined. Although Wolf-Watz et al. (1975) described multiple isolates of $N$. gonorrhoeae with high and low amounts of C18:1, this feature has not been previously reported for meningococcal isolates. In E. coli, the unsaturated fatty acids, palmitoleic acid (C16:1) and cis-vaccenic acid (C18:1), are synthesized by a branched pathway which diverges from that of the saturated fatty acids (Rock et al., 1996). A 3-hydroxydecanoyl-ACP dehydrase encoded by fab $A$ introduces a trans double bond into the acyl chain of $\beta$-hydroxy-decanoyl-ACP, which is then isomerized to cis-3-decanoyl-ACP. This compound serves as the substrate for further elongation cycles catalysed by the $\beta$-ketoacyl-ACP synthetases (FabB and FabF) which extends the acyl chain to form palmitoleoyl-ACP (C16:1 $\Delta 9)$ and cis-vaccenoyl-ACP

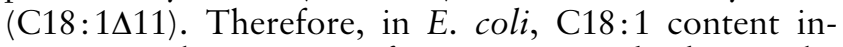
creases at the expense of $\mathrm{C} 16: 1$ primarily due to the activity of the temperature-regulated FabF (Rock et al., 1996). However, we found the relative content of C16:1 did not vary significantly among the different meningococcal isolates with high or low amounts of C18:1, nor was the $\mathrm{C} 18: 1$ content of meningococcal phospholipids temperature-regulated (data not shown). Instead, compared to the other neisserial phospholipids in this report, the phospholipids from N. meningitidis 6940 and N. gonorrhoeae FA 1090 appear to be increased in C18:1 at the expense of C14:0 and not at the expense of C16:1 as is the case for E. coli, suggesting that the enzymic activities of the meningococcal condensing enzymes will be different from those of E. coli.

The recent completion of the genome databases of $N$. meningitidis Z2491 ( $N$. meningitidis sequencing group at the Sanger Center; http://www.sanger.ac.uk) and N. gonorrhoeae FA 1090 (Gonococcal Genome Sequencing Project; http://www.genome.ou.edu) has provided some insight into the genetic basis of the fatty acid biosynthesis pathway in these bacteria. The current model of fatty acid synthesis in E. coli requires two essential condensing enzymes (FabH and FabB), a $\beta$ ketoacyl reductase (FabG), two $\beta$-hydroxyacyl-ACP dehydrases (FabA and FabZ) and an enoyl-ACP reductase (FabI). Although homologues for these enzymes were found in the N. meningitidis Z2491 genome, only a single dehydrase homologue was present, presumably FabZ, since this enzyme is essential for the fatty acid elongation cycle. The absence of a FabA homologue in Neisseria spp. is not unique. A search for clusters of orthologous groups of proteins (COGs) in the complete genomes of 18 organisms (see Entrez genomes at http://www.ncbi.nlm.nih.gov) revealed that only three, E. coli, Haemophilus influenzae and Bacillus subtilis, contain two dehydrases. Six species, including Rickettsia, Chlamydia, Synechocystis, Aquifex, Thermotoga and Helicobacter species, contained a single E. coli dehydrase homologue, while the remainder did not contain any COGs related to the E. coli dehydrase. Therefore, it appears that the production of unsaturated fatty acids in these species, including $N$. meningitidis and N. gonorrhoeae, may proceed via different biochemical pathways to that of E. coli.

The variability of phospholipid structures suggests that outer-membrane biogenesis of meningococci and gonococci may differ from that of E. coli. As noted above, E. coli has one essential LPA acyl transferase, while at least two are found in N. meningitidis. The synthesis of lipid A is also essential for cell viability in E. coli (Nikaido, 1996; Raetz, 1996). In contrast, a meningococcal mutant has been reported to be without lipid A and remains viable (Steeghs et al., 1998). Examination of the outer- 
membrane profile of this meningococcal lipid-A-deficient mutant did not reveal any major alterations in outer-membrane protein expression, although the amount of PE containing shorter acyl chains was increased (Van der Ley et al., 1998). Therefore, the ability of meningococci and gonococci to produce variable phospholipids containing short acyl chains may allow such mutants to functionally replace the absent lipid $\mathrm{A}$ and remain viable.

\section{ACKNOWLEDGEMENTS}

The work described in this report was supported by a grant from the National Institutes of Allergy and Infectious Diseases (PHS grant AI-33517 to D.S.S.) and by a grant from the Department of Energy (DE-FG09-93ER20097) to the Complex Carbohydrate Research Center.

\section{REFERENCES}

Brandtzaeg, P., Kierulf, P., Gaustad, P., Skulberg, A., Bruun, J. N., Halvorsen, S. \& Sorensen, E. (1989). Plasma endotoxin as a predictor of multiple organ failure and death in systemic meningococcal disease. J Infect Dis 159, 195-203.

Cacciapuoti, A. F., Wegener, W. S. \& Morse, S. A. (1978). Cell envelope of Neisseria gonorrhoeae: phospholipase activity and its relationship to autolysis. Infect Immun 20, 418-420.

Cacciapuoti, A. F., Wegener, W. S. \& Morse, S. A. (1979). Phospholipid metabolism in Neisseria gonorrhoeae: phospholipid hydrolysis in nongrowing cells. Lipids 14, 718-726.

Clark, V. L., Campbell, L. A., Palermo, D. A., Evans, T. M. \& Klimpel, K. W. (1987). Induction and repression of outer membrane proteins by anaerobic growth of Neisseria gonorrhoeae. Infect Immun 55, 1359-1364.

Cole, M. J. \& Enke, C. G. (1991). Direct determination of phospholipid structures in microorganisms by fast atom bombardment triple quadrupole mass spectrometry. Anal Chem 63, 1032-1038.

Coleman, J. (1992). Characterization of Escherichia coli cells deficient in 1-acyl-sn-glycerol-3-phosphate acyltransferase activity $\left(p l_{s} C\right)$. Mol Gen Genet 232, 295-303.

Dempsey, J. F. \& Cannon, J. G. (1994). Locations of genetic markers on the physical map of the chromosome of Neisseria gonorrhoeae FA 1090. J Bacteriol 176, 2055-2060.

Drucker, D. B., Megson, G., Harty, D. W. S., Riba, I. \& Gaskell, S. J. (1995). Phospholipids of Lactobacillus spp. J Bacteriol 177, 6304-6308.

Guymon, L. F., Walstad, D. L. \& Sparling, P. F. (1978). Cell envelope alterations in antibiotic-sensitive and -resistant strains of Neisseria gonorrhoeae. J Bacteriol 136, 391-401.

Hancock, R. E. (1997). The bacterial outer membrane as a drug barrier. Trends Microbiol 5, 37-42.

Handsfield, H. H. \& Sparling, P. F. (1995). Neisseria gonorrhoeae. In: Principles and Practice of Infectious Diseases, pp. 103-119. Edited by G. L. Mandell, R. G. Douglas, J. E. Bennett \& R. Dolin. New York: Churchill Livingstone.

Jensen, N. J., Tomer, K. B. \& Gross, M. L. (1987). FAB MS/MS for phosphatidylinositol, -glycerol, -ethanolamine, and other complex phospholipids. Lipids 22, 480-489.

Kahler, C. M. \& Stephens, D. S. (1998). Genetic basis for biosynthesis, structure, and function of meningococcal lipooligosaccharide (endotoxin). Crit Rev Microbiol 24, 281-334.
Kahler, C. M., Carlson, R. W., Rahman, M. M., Martin, L. E. \& Stephens, D. S. (1996a). Two glycosyltransferase genes, $\lg t F$ and $r f a K$, constitute the lipooligosaccharide ice (inner core extension) biosynthesis operon of Neisseria meningitidis. J Bacteriol 178, 6677-6684.

Kahler, C. M., Carlson, R. W., Rahman, M. M., Martin, L. E. \& Stephens, D. S. (1996b). Inner core biosynthesis of lipooligosaccharide (LOS) in Neisseria meningitidis serogroup B: Identification and role in LOS assembly of the $\alpha 1,2 \mathrm{~N}$-acetylglucosamine transferase (rfaK). J Bacteriol 178, 1265-1273.

Karow, M., Fayet, O. \& Georgopoulos, C. (1992). The lethal phenotype caused by null mutations in the Escherichia coli htrB gene is suppressed by mutations in the $a c c B C$ operon, encoding two subunits of acetyl coenzyme A carboxylase. J Bacteriol 174, 7407-7418.

Kloser, A., Laird, M., Ding, M. \& Misra, R. (1998). Modulations in lipid A and phospholipid biosynthesis pathways influence outer membrane protein assembly in Escherichia coli. Mol Microbiol 27, 1003-1008.

Lee, F. K. N., Stephens, D. S., Gibson, B. W., Engstrom, J. J., Zhou, D. \& Apicella, M. A. (1995). Microheterogeneity of Neisseria lipooligosaccharide: analysis of a UDP-glucose 4-epimerase mutant of Neisseria meningitidis NMB. Infect Immun 63, 2508-2515.

Lewis, V. J., Weaver, R. W. \& Hollis, D. G. (1968). Fatty acid composition of Neisseria species as determined by gas chromatography. J Bacteriol 96, 1-5.

Mold, C. (1989). Effect of membrane phospholipids on activation of the alternative complement pathway. J Immunol 143, 16631668.

Moolenaar, W. H. (1995). Lysophosphatidic acid, a multifunctional phospholipid messenger. J Biol Chem 270, 1294912952.

Morse, S. A. \& Bartenstein, L. (1974). Factors affecting autolysis of Neisseria gonorrhoeae. Proc Soc Exp Biol Med 145, 1418-1421.

Moss, C. W., Kellogg, D. S., Jr, Farshy, D. C., Lambert, M. A. \& Thayer, J. D. (1970). Cellular fatty acids of pathogenic Neisseria. J Bacteriol 104, 63-68.

Nassif, X. \& So, M. (1995). Interaction of pathogenic Neisseriae with nonphagocytic cells. Clin Microbiol Rev 8, 376-388.

Nikaido, H. (1996). Outer membrane. In Escherichia coli and Salmonella typhimurium: Cellular and Molecular Biology, pp. 29-47. Edited by F. C. Neidhardt, J. L. Ingraham, K. Brooks Low, B. Magasanik, M. Schaechter \& H. E. Umbarger. Washington, DC: American Society for Microbiology.

Radin, N. S. (1969). Preparation of lipid extracts. Methods Enzymol 14, 245-254.

Raetz, C. R. (1996). Bacterial lipopolysaccharides: a remarkable family of bioactive macroamphiphiles. In Escherichia coli and Salmonella typhimurium: Cellular and Molecular Biology, pp. 1035-1063. Edited by F. C. Neidhardt, J. L. Ingraham, K. Brooks Low, B. Magasanik, M. Schaechter \& H. E. Umbarger. Washington, DC: American Society for Microbiology.

Rock, C. O., Jackowski, S. \& Cronan, J. E., Jr (1996). Lipid metabolism in prokaryotes. In: Biochemistry of Lipids, Lipoproteins and Membranes, pp. 35-74. Edited by D. E. Vance \& J. E. Vance. Amsterdam: Elsevier.

Rottem, S., Markowitz, O. \& Razin, S. (1978). Thermal regulation of the fatty acid composition of lipopolysaccharides and phospholipids of Proteus mirabilis. Eur J Biochem 85, 445-450. 
Sen, K. \& Nikaido, H. (1991). Lipopolysaccharide structure required for in vitro trimerization of Escherichia coli $\mathrm{OmpF}$ porin. J Bacteriol 173, 926-928.

Senff, L. M., Wegener, W. S., Brooks, G. F., Finnerty, W. R. \& Makula, R. A. (1976). Phospholipid composition and phospholipase A activity of Neisseria gonorrhoeae. J Bacteriol 127, 874-880.

Shibuya, I. (1992). Metabolic regulations and biological functions of phospholipids in Escherichia coli. Prog Lipid Res 31, 245-299.

Shih, G. C., Kahler, C. M., Swartley, J. S., Rahman, M. M., Coleman, J., Carlson, R. W. \& Stephens, D. S. (1998). Multiple lysophosphatidic acid acyltransferases in Neisseria meningitidis. Mol Microbiol 32, 942-952.

Smith, P. B., Synder, A. P. \& Harden, C. S. (1995). Characterization of bacterial phospholipids by electrospray ionization tandem mass spectrometry. Anal Chem 67, 1824-1830.

Steeghs, L., Den Hartog, R., Den Boer, A., Zomer, B., Roholl, P. \& Van der Ley, P. (1998). Meningitis bacterium is viable without endotoxin. Nature 392, 449-450.

Stephens, D. S., Swartley, J. S., Kathariou, S. \& Morse, S. A. (1991). Insertion of Tn916 in Neisseria meningitidis resulting in loss of Group B capsular polysaccharide. Infect Immun 59, 4097-4102.

Stephens, D. S., McAllister, C. F., Zhou, D., Lee, F. K. \& Apicella, M. A. (1994). Tn916-generated, lipooligosaccharide mutants of Neisseria meningitidis and Neisseria gonorrhoeae. Infect Immun 62, 2947-2952.

Sud, I. J. \& Feingold, D. S. (1976). Phospholipids and fatty acids of Neisseria gonorrhoeae. J Bacteriol 124, 713-717.

Swartley, J. S. \& Stephens, D. S. (1994). Identification of a genetic locus involved in the biosynthesis of $\mathrm{N}$-acetyl-D-mannosamine, a precursor of the $(\alpha 2 \rightarrow 8)$-linked polysialic acid capsule of serogroup B Neisseria meningitidis. J Bacteriol 176, 1530-1534.

Swartley, J. S., Liu, L., Miller, Y. K., Martin, L. E., Edupunganti, S. \& Stephens, D. S. (1998). Characterization of the gne cassette required for biosynthesis of the ( $\alpha 1-6)$ linked $N$-acetyl-Dmannosamine-1-phosphate capsule of serogroup A Neisseria meningitidis. J Bacteriol 180, 1533-1539.

Van der Ley, P., Hamstra, H. J. \& Steeghs, L. (1998). Modification of lipid A biosynthesis in Neisseria meningitidis. In Abstracts of the 11th Pathogenic Neisseria Conference, abstract no. 27. Paris, France: Editions EDK.

Virji, M. (1996). Meningococcal disease: epidemiology and pathogenesis. Trends Microbiol 4, 466-470.

Wilkinson, S. G. (1988). Gram-negative bacteria. In Microbial Lipids, pp. 299-488. Edited by C. Ratledge \& S. G. Wilkinson. London: Academic Press.

Wolf-Watz, H., Elmros, T., Normark, S. \& Bloom, G. D. (1975). Cell envelope of Neisseria gonorrhoeae: outer membrane and peptidoglycan composition of penicillin-sensitive and -resistant strains. Infect Immun 11, 1332-1341.

York, W. S., Darvill, A. G., McNeil, M., Stevenson, T. T. \& Albersheim, P. (1985). Isolation and characterization of plant cell walls and cell wall components. Methods Enzymol 118, 3-40.

Yruela, I., Barbe, A. \& Grimalt, J. O. (1990). Determination of double bond position and geometry in linear and highly branched hydrocarbons and fatty acids from gas chromatography-mass spectrometry of epoxides and diols generated by stereospecific resin hydration. J Chromatogr Sci 28, 421-427.

Zhou, D., Stephens, D. S., Gibson, B. W., Engstrom, J. J., McAllister, C. F., Lee, F. K. N. \& Apicella, M. A. (1994). Lipooligosaccharide biosynthesis in pathogenic Neisseria. Cloning, identification, and characterization of the phosphoglucomutase gene. J Biol Chem 269, 11162-11169.

Zollinger, W. D. \& Mandrell, R. E. (1977). Outer-membrane protein and lipopolysaccharide serotyping on Neisseria meningitidis by inhibition of a solid-phase radioimmunoassay. Infect Immun 18, 424-433.

Received 6 March 2000; revised 11 May 2000; accepted 18 May 2000. 